\title{
Clinicopathological and Radiological Profile of Multinodular Goitre - A Prospective Study
}

https://doi.org/10.47210/bjohns.2021.v29i2.479

Koustav Mondal, ${ }^{1}$ Chiranjib Das ${ }^{2}$

$\underline{\text { Introduction }}$

\section{ABSTRACT}

Multinodular goitre (MNG) is defined as multiple palpable distinct nodules in the enlarged thyroid gland. MNG can harbour malignancy in 1-10\% cases. We undertook the present study to correlate the clinical, radiological and cytological features of $M N G$ with that of final histopathological diagnosis.

\section{Materials and Methods}

A prospective cohort study was done in a tertiary care hospital in northern part of West Bengal from January 2018 to December 2019. Patients aged between 12 years and 75 years, presenting with MNG on clinical examination, were included in the study. We compared the pre-operative ultrasonography (USG) of neck and fine needle aspiration cytology (FNAC) reports with post-operative histopathological examination (HPE) report.

\section{$\underline{\text { Results }}$}

Among 100 patients 80 were female and 20 were male. Most patients were in $41-50$ years age group. For detection of malignancy in MNG, USG had 40\% sensitivity, $97.78 \%$ specificity, $66.67 \%$ positive predictive value (PPV), $93.62 \%$ negative predictive value (NPV), and 92\% diagnostic accuracy. Sensitivity, specificity, PPV, NPV and diagnostic accuracy of FNAC for detection of malignancy in $M N G$ were $20 \%, 93.33 \%, 25 \%, 91.3 \%$ and $86 \%$ respectively. When USG features were combined with FNAC features non-diagnostic result decreased from $6 \%$ to $2 \%$ and diagnostic accuracy for detecting malignancy in $M N G$ increased from $86 \%$ to $90 \%$.

\section{Conclusion}

USG and FNAC are complementary to each other in the diagnostic workup of MNG. USG guided FNAC is still better for reaching final diagnosis and exclusion of malignancy..

$\underline{\text { Keywords }}$

Goiter, Multinodular; Ultrasonography; Cytodiagnosis; Histopathology

$\mathrm{M}$ ultinodular goitre (MNG) is defined as the palpation of multiple distinct nodules in the enlarged thyroid gland. MNG is the most common thyroid problem, encountered in up to $5 \%$ of

1 - Department of General Surgery, Maharaja Jitendra Narayan Medical College and Hospital, Cooch Behar, West Bengal

2 - Department of ENT, Maharaja Jitendra Narayan

Medical College and Hospital, Cooch Behar, West Bengal

\section{Corresponding author:}

Dr Chiranjib Das

email: chirubata.das.87@gmail.com the general population. ${ }^{1}$ The aetiopathogenesis of MNG is not very clear. A mild dietary deficiency of iodine, slight impairment of hormone synthesis, increased iodide clearance from the kidneys, and the presence of thyroidstimulating immunoglobulins have been suggested as the various causes. ${ }^{1}$ MNG can harbour malignancy in $1-10 \%$ cases. ${ }^{1}$ Hence accurate diagnosis and appropriate management of $\mathrm{MNG}$ is important. It is often impossible to clinically diagnose malignancy in MNG.

A careful physical examination along with relevant investigations such as ultrasonography (USG) of neck and fine needle aspiration cytology (FNAC) are required to reach an exact diagnosis and plan management 
accordingly. We undertook this present study to correlate the clinical, radiological and cytological features of MNG with the final histopathological diagnosis along with a review of the relevant literature.

\section{Materials and Methods}

A prospective cohort study was undertaken in a tertiary care hospital in Northern part of West Bengal from January 2018 to December 2019. Institutional ethics committee clearance was obtained. Patients between 12 years and 75 years of age presenting with MNG by clinical examination were included in the study. Patients with solitary thyroid nodule, hypo or hyperthyroidism, retrosternal goitre, cervical lymphadenopathy or history of previous thyroid surgery were excluded from the study. Patients with at least one of the following criteria were posted for surgery: suspicion of malignancy, rapid nodule growth, compressive symptom, nodule larger than $4 \mathrm{~cm}$, non-diagnostic FNAC on more than one occasion, as well as those who expressed desire of being intervened either for aesthetic reasons or for uneasiness with the diagnosis. Patients who were not fit for surgery or refused surgery were excluded. Informed consent was taken from all participants or their guardians.

After taking proper history and clinical examination all patients were subjected to blood thyroid stimulating hormone (TSH) estimation, USG of neck, and FNAC from thyroid nodule. USG neck was performed to describe the presence or absence of the following parameters: echogenicity, microcalcifications, irregular borders, intra-nodular increase in central vascularization and presence of a halo. According to ultrasound characteristics, patients were classified into two groups. "Benign" if they had one or no malignant features, "Suspicious of malignancy" when they had two or more malignant features. FNAC was done from the most suspicious nodule by palpation method. FNAC report was classified as "Non-diagnostic or unsatisfactory", "Benign", "Suspicious of malignancy", and "Malignant".

Patients were posted for surgery after performing all routine pre-operative investigations. Based on the USG and FNAC findings different grades of thyroidectomy were performed. Hemithyroidectomy was done in case
Table I: Distribution of patients according to age and final HPE report

\begin{tabular}{|c|c|c|}
\hline $\begin{array}{c}\text { AGE GROUP } \\
\text { (YEARS) }\end{array}$ & BENIGN & MALIGNANT \\
\hline $21-30$ & 10 & 1 \\
\hline $31-40$ & 40 & 2 \\
\hline $41-50$ & 40 & 5 \\
\hline $51-60$ & 0 & 1 \\
\hline $61-70$ & 0 & 1 \\
\hline
\end{tabular}

of non-diagnostic or benign lesions involving single lobe. Near total thyroidectomy was done in case of nondiagnostic or benign lesions involving both lobes. Total thyroidectomy was done in case of lesions suspicious of malignancy and malignant lesions. All specimens were sent for histopathological examination (HPE). We compared the pre-operative USG and FNAC reports with post-operative HPE report.

\section{Results}

Among 100 patients 80 were female and 20 were male. $45 \%$ patients were in $41-50$ years age group, while $42 \%$ patients were in $31-40$ years age group. None of these patients had history of irradiation to neck or family history of thyroid malignancy. Most of the malignancy was found in 41-50 years age group. (Table I) 94 patients had benign USG features and 6 patients had features suspicious of malignancy. (Table II) FNAC was non-diagnostic in 6 patients, benign in 86 patients and suspicious of malignancy in 8 patients. (Table III)

Table II: Comparison of pre-operative USG report with post-operative HPE report

\begin{tabular}{|c|c|c|}
\hline \multirow{2}{*}{ USG REPORT } & \multicolumn{2}{|c|}{ HPE REPORT } \\
\cline { 2 - 3 } Benign & BENIGN & MALIGNANT \\
\hline $\begin{array}{c}\text { Suspicious of } \\
\text { malignancy }\end{array}$ & 2 & 6 \\
\hline
\end{tabular}


Table III: Comparison of pre-operative FNAC report with post-operative HPE report

\begin{tabular}{|c|c|c|}
\hline \multirow{2}{*}{ FNAC REPORT } & \multicolumn{2}{|c|}{ HPE REPORT } \\
\cline { 2 - 3 } & BENIGN & MALIGNANT \\
\hline Non-diagnostic & 2 & 4 \\
\hline Benign & 82 & 4 \\
\hline $\begin{array}{c}\text { Suspicious of } \\
\text { malignancy }\end{array}$ & 6 & 2 \\
\hline
\end{tabular}

After combining the USG and FNAC features it was non-diagnostic in 2 patients, benign in 86 patients, and suspicious of malignancy in 12 patients. (Table IV) Post-operative HPE report was benign in 90 patients and malignant in 10 patients. (Table II, III, IV) Seven (7) patients had papillary carcinoma, 2 patients had follicular carcinoma, and 1 patient had medullary carcinoma. So, for detection of malignancy in MNG, USG had $40 \%$ sensitivity, $97.78 \%$ specificity, $66.67 \%$ positive predictive value (PPV), 93.62\% negative predictive value (NPV), and 92\% diagnostic accuracy. (Table II). Similarly, sensitivity, specificity, PPV, NPV and diagnostic accuracy of FNAC for detection of malignancy in MNG were 20\%, 93.33\%, 25\%, 91.3\% and $86 \%$ respectively. (Table III) The combination of USG and FNAC had 60\% sensitivity, 93.33\% specificity, 50\% PPV, 95.45\% NPV and 90\% diagnostic accuracy. (Table IV) Based on the combined features of USG and FNAC, hemithyroidectomy, near total thyroidectomy and total thyroidectomy were done in 14 , 74 and 12 patients respectively. Surgery was adequate in 90 patients. 4 patients had to undergo completion thyroidectomy. 6 patients were overtreated which was taken care of with appropriate medical therapy.
Table IV: Comparison of combined USG and FNAC report with post-operative HPE report

\begin{tabular}{|c|c|c|}
\hline \multirow{2}{*}{$\begin{array}{c}\text { USG + FNAC } \\
\text { REPORT }\end{array}$} & \multicolumn{2}{|c|}{ HPE REPORT } \\
\hline Non-diagnostic & 2 & 0 \\
\hline Benign & 82 & 4 \\
\hline $\begin{array}{c}\text { Suspicious of } \\
\text { malignancy }\end{array}$ & 6 & 6 \\
\hline
\end{tabular}

(Table V) In the total thyroidectomy group 4 patients developed transient hypocalcaemic crisis and 1 patient suffered recurrent laryngeal nerve palsy. In the near total thyroidectomy group 1 patient ended up with recurrent laryngeal nerve palsy. None in the hemithyroidectomy group had suffered from any such complication.

\section{Discussion}

MNG is more common in women than men and increases in prevalence with age. ${ }^{2}$ In the present study, $80 \%$ patients were females which is comparable to the results of Zambudio et al. which showed $89 \%$ incidence in females. ${ }^{3}$ Majority of patients in the present study were in the 41-50 years age group, followed by the age group of 31-40 years. This is comparable to the analysis of 1280 cases by Bremer and Night, which showed maximum incidence between 40 and 50 years. ${ }^{4}$

FNAC is the gold standard diagnostic modality for evaluating patients with MNG. FNAC is safe, rapid, inexpensive and reliable. It is possible to classify nonneoplastic and neoplastic lesions with the help of FNAC. ${ }^{5}$ However, there are limitations to palpation guided

Table V: Adequacy of different types of thyroidectomy based on the combined USG and FNAC report

\begin{tabular}{|c|c|c|c|}
\hline \multirow{2}{*}{ TYPE OF SURGERY } & \multicolumn{3}{|c|}{ ADEQUACY OF SURGERY } \\
\cline { 2 - 4 } & ADEQUATE & UNDERTREATED & OVERTREATED \\
\hline Hemithyroidectomy & 11 & 3 & 0 \\
\hline Near total thyroidectomy & 73 & 1 & 0 \\
\hline Total thyroidectomy & 6 & 0 & 6 \\
\hline
\end{tabular}


approach. These are difficulty in sampling nodules that are small or non-palpable, indistinct, posterior or deep in location, and cystic. These factors lead to a nondiagnostic cytology of 5-43\%. ${ }^{6}$ In the present study FNAC was non-diagnostic in $6 \%$ patients. Studies have shown a decrease in the number of non-diagnostic samples with USG guided FNAC. ${ }^{7}$ In a study done by B.R. Ashwini et al. the statistical evaluation showed $44.4 \%$ sensitivity, $100 \%$ specificity, $100 \%$ PPV, $79.2 \%$ NPV and $82.1 \%$ diagnostic accuracy on conventional FNAC and $77.8 \%$ sensitivity, $100 \%$ specificity, $100 \%$ PPV, 90.4\% NPV and 92.9\% diagnostic accuracy on USG guided FNAC. ${ }^{8}$ Sensitivity, specificity, PPV, NPV and diagnostic accuracy of FNAC for detection of malignancy in MNG in the present study were $20 \%$, $93.33 \%, 25 \%, 91.3 \%$ and $86 \%$ respectively. Nonavailability of the USG guided FNAC was one of the limitations of the present study.

There was a decline in the use of USG in MNG in many parts of the world because it had minimal impact on management. ${ }^{9}$ But it is becoming popular again as an adjunct to FNAC. In India it continues to be widely used in the initial evaluation of MNG. The reasons for its widespread popularity are the relatively low cost, easy availability and non-invasive nature. In cases with overlapping FNAC features, USG helps in differentiating and providing more accurate diagnosis of some of the lesions. ${ }^{9}$ In a study done by Rabal Fueyo A et al. USG had a sensitivity of $32 \%$, specificity of $93 \%$, PPV of $73 \%$ and NPV of $67 \% .^{10}$ In the present study for detection of malignancy in MNG, USG had $40 \%$ sensitivity, $97.78 \%$ specificity, $66.67 \%$ PPV, $93.62 \%$ NPV, and 92\% diagnostic accuracy. In our study when USG features were combined with FNAC features non-diagnostic result decreased from $6 \%$ to $2 \%$ and diagnostic accuracy for detecting malignancy in $\mathrm{MNG}$ increased from $86 \%$ to $90 \%$.

The extent of surgery in MNG is controversial. Multiple revision surgeries are not possible on thyroid due to its location and it is also difficult to obtain the patient's consent for the same. ${ }^{8}$ Moreover, subsequent surgeries had higher chances of complications like hypoparathyroidism and recurrent laryngeal nerve palsy. ${ }^{11}$ Recurrence of goitre after surgery is least after total thyroidectomy. However the patient becomes permanently hypothyroid after total thyroidectomy. So total thyroidectomy is reserved for malignant and suspicious lesions on USG and/or FNAC. ${ }^{7}$ Near total thyroidectomy provides a safer and effective alternative to total thyroidectomy in benign lesions. ${ }^{4,9,11}$ In the present study near total thyroidectomy was the most commonly performed procedure followed by hemithyroidectomy. Total thyroidectomy was done in lesions suspicious of malignancy on USG and/or FNAC.

\section{Conclusion}

Though FNAC is very useful in diagnosis and management of MNG, one should not rely solely on it. Malignancy can still come as a surprise on postoperative HPE. USG guided FNAC is a much better option in reaching final diagnosis and exclusion of malignancy in MNG.

\section{References}

1. Abu-Eshy SA, Khan AR, Khan GM, al-Humaidi MA, al-Shehri MY, Malatani TS. Thyroid malignancy in multi-nodular goitre and in a solitary nodule. J R Coll Surg Edinb. 1995; 40:310-2

2. Taylor S. The evolution of nodular goiter. J Clin Endocrinol Metab. 1953; 13(10):1232-47

3. Zambudio AR, Rodríguez J, Riquelme J, Soria T, Canteras M, Parrilla P. Prospective study of postoperative complications after total thyroidectomy for multinodular goiters by surgeons with experience in endocrine surgery. Ann Surg. 2004; 240:1825

4. Amudhan J, Vijay A, Latha G, Anandan H. Clinicopathological Study on Multinodular Goiter: A Prospective Study. Int J Sci Stud. 2017; 5(1):83-5

5. Cappel RJ, Bouvy ND, Bonjer HJ, Muiswinkel JM, Chadha S. Fine needle aspiration of thyroid nodules: How accurate it is and what are the causes of discrepant cases? Cytopathology 2001; 12:399-405

6. Prades JM, Dumollard JM, Timoshenko A, Chelikh L, Michel F, Estour B, et al. Multinodular goiter: surgical management and histopathological findings. Eur Arch Otorhinolaryngol. 2002; 259:217-21

7. Martinek A, Dvorackova J, Honka M, Horacek J, Klvana P Importance of guided fine needle aspiration cytology (FNAC) for the diagnostics of thyroid nodules - own experience. Biomed Pap Med Fac Univ Palacky Plomouc Czech Repub. 2004; 148(1):45-50

8. B R Ashwini, Vernekar Sunita, Kulkarni Mohan H, T Kiran. Comparitive Study of Conventional and Ultrasound-guided 
Fine Needle Aspiration Cytology of Thyroid in a Tertiary Care Center of North Karnataka. Int J Cur Res Rev. 2012; 04(21):649

9. Nilakantan A, Venkatesh MD, Raghavan $\mathrm{D}$ et al. Ultrasonography: Its role in nodular thyroid disease. Indian $\mathrm{J}$ Otolaryngol Head Neck Surg. 2007;59:332-35

10. Rabal Fueyo A, Vilanova Serra M, Lerma Puertas E, et al.
Diagnostic accuracy of ultrasound and fine-needle aspiration in the study of thyroid nodule and multinodular goitre. Endocrinol Diab Metab. 2018; 1:e24

11. Sanjeeva KK, Chandra B, Balakrishna MA, et al Clinicoepidemiological study and treatment outcome of multinodular goitre at a tertiary care hospital. Journal of Clinical and Diagnostic Research. 2015; 9(6):22-5. 